\title{
"Pyridopyridazine": A Versatile Nucleus in Pharmaceutical Field
}

\author{
Mohamed A. Ibrahim 1,2,3, Ahmed H. Elmenoufy4,5, Mohamed Elagawany, ${ }^{1,6}$, \\ Mohammed M. Ghoneim ${ }^{7,8}$, Alaa Moawad ${ }^{9}$ \\ ${ }^{1}$ Department of Chemistry, University of Florida, Gainesville, USA \\ ${ }^{2}$ Department of Organic Chemistry, College of Pharmacy, Misr University for Science and Technology, 6th of \\ the October City, Egypt \\ ${ }^{3}$ Department of Pharmaceutical Chemistry, College of Pharmacy, Almaarefa Colleges for Science and \\ Technology, Riyadh, Saudi Arabia \\ ${ }^{4}$ Department of Pharmaceutical Chemistry, College of Pharmacy, Misr University for Science and Technology, \\ 6th of the October City, Egypt \\ ${ }^{5}$ Department of Pharmaceutical Engineering, National Research Centre of Nanomedicine, Huazhong University \\ of Science and Technolgy, Wuhan, China \\ ${ }^{6}$ Department of Pharmaceutical Chemistry, Faculty of Pharmacy, Damanhour University, Damanhour, Egypt \\ ${ }^{7}$ Department of Pharmacognosy, Faculty of Pharmacy, the University of Al-Azhar, Cairo, Egypt \\ ${ }^{8}$ Department of Natural products, School of Pharmacy, Almaarefa Colleges for Science and Technology, \\ Riyadh, Saudi Arabia \\ ${ }^{9}$ Department of Pharmacognosy, Faculty of Pharmacy, King Saud University, Riyadh, Saudi Arabia \\ Email: drmmonem@yahoo.com
}

Received 14 August 2015; accepted 9 October 2015; published 12 October 2015

Copyright (C) 2015 by authors and Scientific Research Publishing Inc.

This work is licensed under the Creative Commons Attribution International License (CC BY).

http://creativecommons.org/licenses/by/4.0/

(c) (i) Open Access

\begin{abstract}
Pyridopyridazines are an important kind of nitrogen atom containing heterocyclic compounds due to their synthetic and pharmacological versatility. This fused heterocycle system represents a common structural feature for many bioactive compounds showing a variety of pharmacological activities which makes it an attractive scaffold for the design and development of new drugs. This mini review summarizes an updated information described in recent literature, about the most relevant pharmacological properties of pyridopyridazines derivatives.
\end{abstract}

\section{Keywords}

Pyridopyridazine, Pyridopyridazinone, Azaheterocycles, Miretilan

How to cite this paper: Ibrahim, M.A., Elmenoufy, A.H., Elagawany, M., Ghoneim, M.M. and Moawad, A. (2015) "Pyridopyridazine": A Versatile Nucleus in Pharmaceutical Field. Journal of Biosciences and Medicines, 3, 59-66.

http://dx.doi.org/10.4236/jbm.2015.310008 


\section{Introduction}

Heterocyclic compounds constitute a huge group of organic compounds playing a key role in drug discovery because of their biological properties. Therefore, several heterocycles are fundamental for life of plants and animals, such as the heme group of chlorophylls and haemoglobin or the nitrogen bases and sugars of nucleic acids, and many of them are nitrogen containing heterocycles. From a Medicinal Chemistry point of view, the introduction of azaheterocycles is interesting because it may modify the electron distribution inside the scaffold leading to a modification of the chemical and physical properties of the compounds (solubility, polar surface area, etc). In addition to modification of the scaffold reactivity towards metabolic pathways, along with is its capacity to cross biological barriers [1].

Pyridopyridazines are structurally related to phthalazines, which have been extensively described in the medicinal chemistry literature as an interesting scaffold. The introduction of a nitrogen atom into the benzo ring of phthalazines leads to pyridopyridazines. This scaffold can be easily functionalized at various ring positions, which makes it an attractive synthetic compound for designing and development of the novel pyridopyridazine drugs. There are 8 isomeric forms of pyridopyridazines [2] (Figure 1).

It is noteworthy to denote that pyridopyridazine nucleus attracted many international leading pharmaceutical companies for their reasonable biological activities. Novartis and Hexal launched miretilan ${ }^{\circledR}$ and Arritlan ${ }^{\circledR}$ respectively as clinically approved antihypertensive drugs have Endralazine Mesylate as active ingredient with pyridopyridazine core moiety [3] [4]. Merck Sharp \& Dohm limited played a great efforts on pyridopyridazine nucleus in CNS related diseases [5]. In addition, Glaxo Smith Kline patented novel pyridopyridazines with antihistaminic activities [6].

Recently, some new pharmaceutical development potentials have been realized with this class of compounds. Some pyrido[2,3-d]- and pyrido[3,4-d]pyridazines were found as protein kinase, especially p38 kinase, inhibitors for treating inflammation and related conditions including rheumatoid arthritis, psoriasis, and other inflammation disorders [7] [8]. A range of pyridopyridazinones have been assayed as potential analgesic agents and showed antinociceptive activity [9]. Some pyridopyridazie derivatives were studied for the treatment of tumors driven by inappropriate hedgehog signaling and demonstrated antagonism of human smoothened with $\mathrm{IC}_{50}$ less than $1 \mu \mathrm{M}$ [10]. In addition, this nucleus showed antiasthmatic [11], antidiabetic [12], antituberculosis [13], and antimicrobial activities [14] (Figure 2).

However, pyridopyridazine system is a versatile scaffold in Medicinal Chemistry which provides derivatives able to interact with different kinds of biological targets, comprehensive report on different activities of pyridopyridazine based compounds is not available in literature till now. The present minireview summarizes the current information about the relevant pharmacological activites of pyridopyridazines derivatives (Figure 2).

\section{Pharmacological Activities}

\subsection{Anti-Inflammatory and Analgesic Activity}

Protein kinases are a big family of enzymes, which trigger the phosphorylation of target protein substrates. Among these kinases, P38 kinase which is mediated in the regulation of Interleukin-I (IL-1) and Tumor Necrosis factor $\alpha$ (TNF- $\alpha$ ) as pro-inflammatory cytokines secreted by macrophage and monocytes in response of inflammatory stimuli as Lipopolysaccharide (LPS). High expression of TNF- $\alpha$ is implicated in triggering many diseases as rheumatoid arthritis (RA), osteoarthritis, inflammatory bowel disease [7].

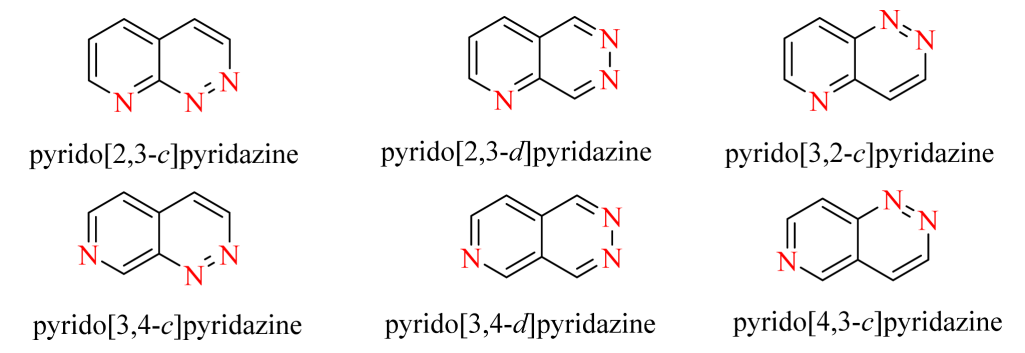

Figure 1. Isomeric pyridopyridazines. 


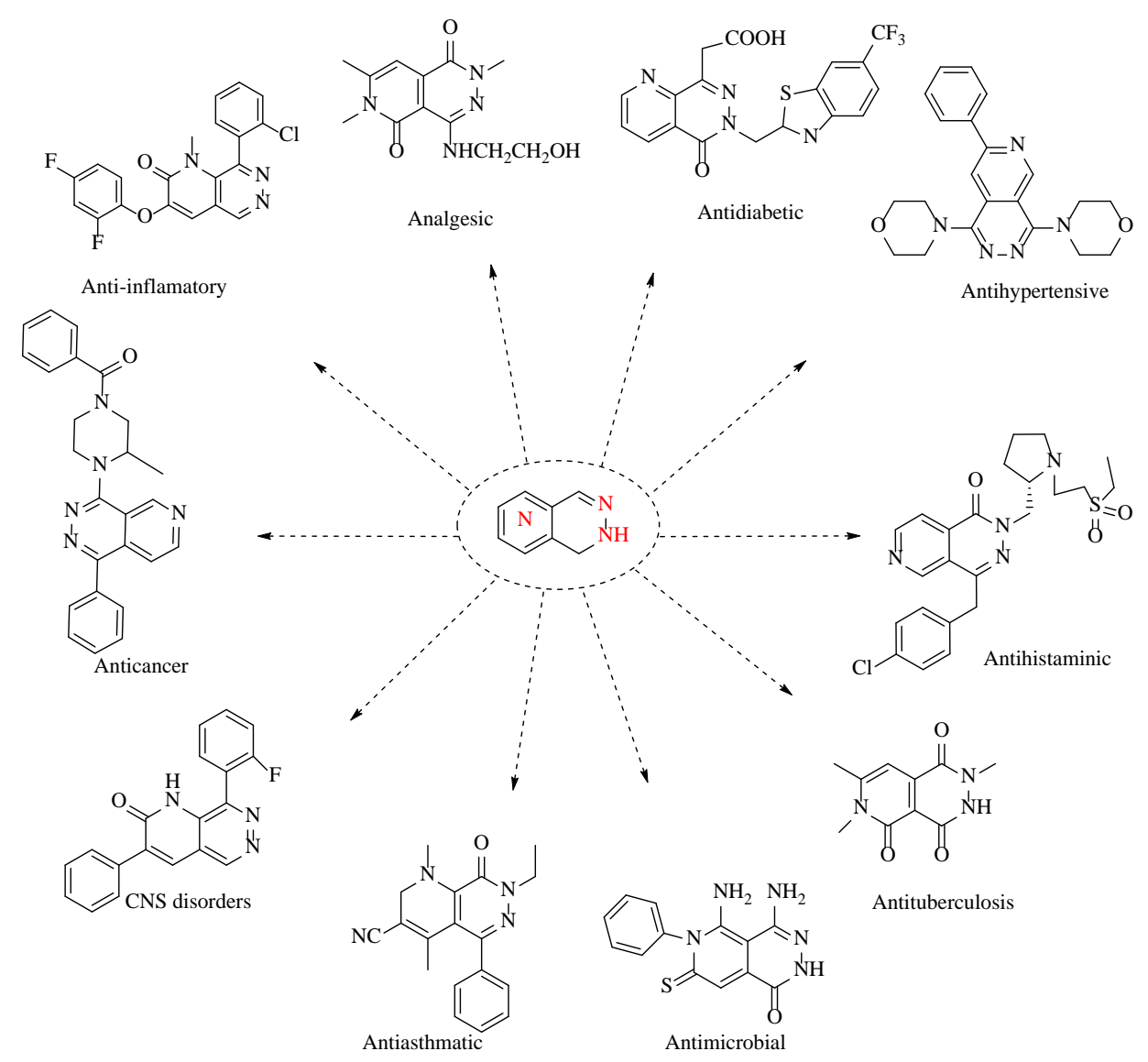

Figure 2. Several pyridopyridazine derivatives with relevant therapeutic applications.

In 2009, Pettus, L, H. Patented a new set of pyrido[2,3-d]pyridazine-2(1H)-one derivatives which are useful in prophylaxis and treatment of protein kinase mediated inflammation and related diseases e.g. rheumatoid arthritis, pulmonary diseases, pain. Among these compounds, compounds $\mathbf{1 a}, \mathbf{b}$ and $\mathbf{2}$ showed the most potent activity in treatment of P38-kinase mediated diseases [7]. In 2011, R. M. Tynebor et al., Merck sharp \& dohme, developed a new class of p38 $\alpha$ selective pyridopyridazin-6-one series from the p38 $\alpha / \beta$ dual inhibitor with highselectivity, potency and with favor of suppressing lipopolysaccharide (LPS) induced TNF $\alpha$ production (proinflammatory cytokines) which resulting in effective therapeutically response against autoimmune driven diseases as rheumatoid arthritis. Form this new class, compound $\mathbf{3}$ is one of the most active derivatives in suppressing TNF $\alpha$ levels in LPS rodent model [8]. One year later, the same authors studied the structural activity relationship for the previously mentioned pyridopyridazin-6-one scaffold. They discovered compound $\mathbf{4}$ which has subnanomolar $\mathrm{p} 38 \alpha$ activity with moderate $\mathrm{p} 38 \beta$ isoform selectivity [15] (Figure 3).

Pain is an unpleasant sensory and emotional experience associated with potential or actual tissue damage [16]. Pain represents a major symptom of many pathological conditions and millions of people worldwide must use analgesic agents in order to treat different types of pain. In 1998, H. Sladowska et al. synthesized a set of 4-aminosubstituted-2,6,7-trimethyl-1,5-dioxo-1,2,5,6-tetrahydropyrido[3,4-d]pyridazines which significantly inhibit the spontaneous locomotors activity and decrease the excitatory action of amphetamine and exerted analgesic properties in mice. From this set of compounds, compounds 5a-c showed strong analgesic activity as assayed in the "writhing syndrome" test. While, compounds 5a,b suppressed spontaneous locomotors activity [17]. In 2009, W. Pakulska et al. synthesized a new series of N-(dimethylamino) ethyl pyridopyridazinones. The compounds have been assayed for their analgesic effect in the hot-plate, tail-flick, and writhing tests [9]. Among them, compounds $\mathbf{6 a}, \mathbf{b}$ exhibited potent analgesic activity [9]. While, compound $\mathbf{7}$ showed a potent analgesic and anti-inflammatory activity [18] (Figure 4). 

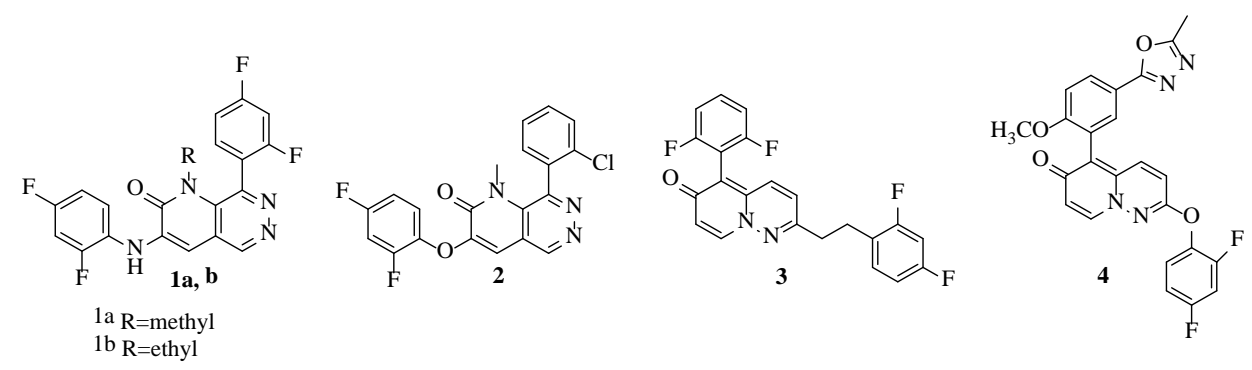

Figure 3. Pyridopyridazine derivatives as anti-inflammatory agents.
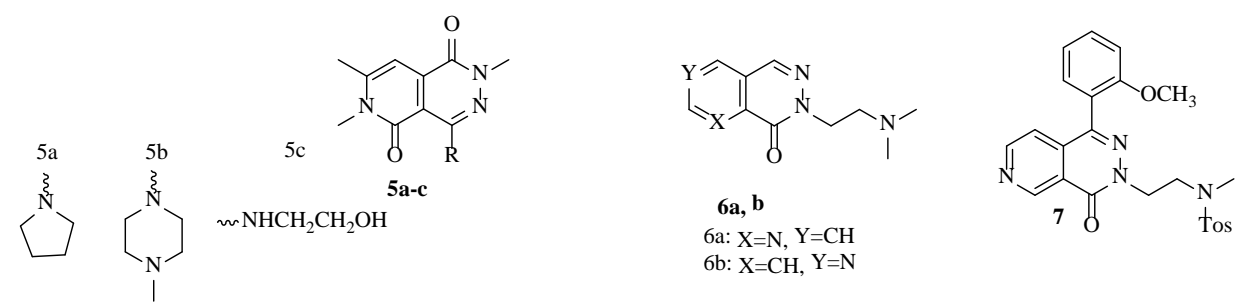

Figure 4. Pyridopyridazine derivatives as analgesic agents.

\subsection{Antihypertensive Activity}

Hypertension is a leading risk factor for cardiovascular disease development like coronary disease, myocardial infarction or stroke being also a recognized contributor to sudden death as well as to congestive cardiac failure and renal insufficiency. Therefore, antihypertensive agents are of critical importance in order to achieve a better control of blood pressure. In 1975, Nishikawa et al. have synthesized a series of substituted-pyridopyridazine derivatives. The compounds have excellent diuretic activity and different characters from known diuretics such as thiazides, carbonic anhydrase inhibitors or furosemide. Among these compounds, Compound $\mathbf{8}$ showed an excellent diuretic activity [19].

Endralazine "compound 9" is clinically approved direct acting vasodilator which resembles Hydralazine in chemical structure. Despite the close relationship, Endralazine is about five times more potent than Hydralazine and that allowing lower dosage usage. Thus, less immunological response would be achieved [3] [4] (Figure 5).

\subsection{Central Nervous System Activities}

In 2001, A. Mitchinson et al., Merck Sharp \& Dohme Limited, filed a patent for a new series of pyrido[2,3-d] pyridazine. These derivatives are a selective ligands for $\mathrm{GABA}_{\mathrm{A}}$ receptors and therefore they are used in treatment a variety of disorders of the central nervous system. Such as, anxiety, panic disorder, animal phobia, social phobia, psychotic disorder. Such as, schizophrenia. Compound $\mathbf{1 0}$ showed the highest activity. It has a Ki value for displacement of [3H]-flumazenil from the $\alpha 2$ and/or $\alpha 3$ and/or $\alpha 5$ subunit of the human $\mathrm{GABA}_{\mathrm{A}}$ receptor of $100 \mathrm{nM}$ [5]. 2 years later, the same company filed another patent for a new class of substituted pyrido[2,3-c] pyridazine derivatives as a useful treatment in the therapy of neorolgical disorders. Among these series of pyrido[2,3-c]pyridazine, compound $\mathbf{1 1}$ has a Ki value for displacement of [3H]-flumazenil from the $\alpha 2$ and/or $\alpha 3$ and/or $\alpha 5$ subunit of the human $\mathrm{GABA}_{\mathrm{A}}$ receptor less than $100 \mathrm{nM}$ [20] (Figure 4). 3 years later, the inventors of the first patent, developed a novel derivatives of 2,3,8-trisubstituted pyrido[2,3-d]pyridazine, Compounds $\mathbf{1 0}$ and 12, with two different synthetic methods. The new derivatives revealed high affinity ligands for the GABA receptor benzodiazepine binding site [21] (Figure 6).

\subsection{Antihistaminic Activity}

Allergic rhinitis and allergic processes in general are mediated by histamine, an intracellular chemical messenger which is released from several cells and specifically by mast cells. In 2008, S. Vile, Glaxo Group Limited, patented a new class of substituted derivatives of pyrido[3,4-d]pyridazine 13a-c. The new compounds were found to have antihistaminic action which could be useful in treatment of inflammatory and allergic diseases of the 
respiratory tract such as bronchitis, allergic rhinitis, asthma, chronic obstructive pulmonary disease. Compound 13a showed a potent H1 receptor antagonist. It exhibited a longer duration of action than Azelastine [6] (Figure 7).

\subsection{Antiasthmatic Activity}

Bronchial asthma is a lung disease characterized by airway obstruction, inflammation and hyperresponsiveness [22].

In 1995 R. Whilhelm, reported a series of pyrido-[2,3-d]pyridazinones as potent and selective Type IV Phosphodiesterase Inhibitors (14a-c). These inhibitors are promising drugs in the treatment of asthma, inflammation [11].

In 1997, V. Dal Piaz et al. synthesized a group of heterocyclic-fused pyridazinones as selective phosphodiesterase (PDE) IV inhibitors. Among these heterocycles, Compound 15, pyrido[2,3-d]pyridazinone, exhibited a good balance of potency and selectivity versus PDE IV and it displayed an affinity for Rolipram binding site by 2 orders of magnitude lower than Rolipram [23] (Figure 8).

\subsection{Antidiabetic Activity}

Diabetes mellitus is a chronic multifactorial disease characterized by a high blood glucose concentration (hyperglycemia). This complex disorder resulting from insulin deficiency (type I diabetes) or insulin resistance (type II diabetes), disturbs the metabolism of carbohydrates, fats and proteins giving rise to not only acute but also longterm complications. More than $90 \%$ of diabetic patients suffer from type II diabetes, i.e. non-exogenous insulin dependent diabetes [24].

Increased glucose flux through the sorbitol pathway, which is mediated by the enzyme aldose reductase, has been implicated in the pathogenesis of diabetic complications. So, the discovery and development of aldose reductase inhibitors (ARIs) as potential therapeutic agents for alleviating these complications was important aim. In 1991, Mylari et al. synthesized a series of pyrido[2,3-d]pyridazin-5-yl)acetic acid, its ester 16a-c, 17a,b and evaluated their activity for inhibition of aldose reductase. Compound $\mathbf{1 6 b}$ showed potent aldose reductase inhibitory activity [12] (Figure 9).
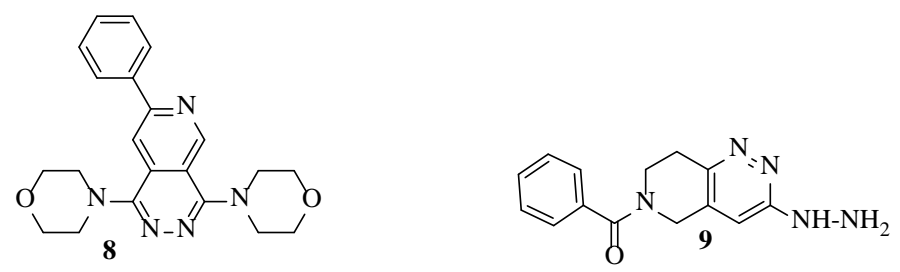

Figure 5. Pyridopyridazine derivatives as antihypertensive agents.
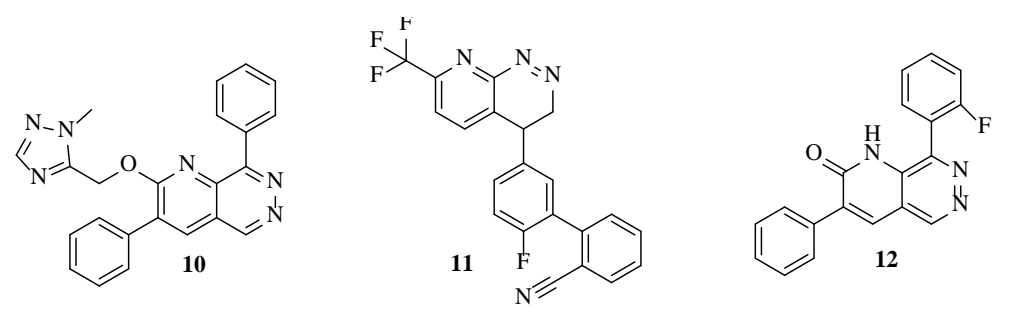

Figure 6. Pyridopyridazine derivatives useful in treatment of neurological disorders.<smiles>CCS(=O)(=O)N1C2CCC1C(Cn1nc(Cc3ccc(Cl)cc3)c3cnccc3c1=O)C2</smiles><smiles>CCCNC(=O)NCCN1CCC[C@H]1Cn1nc(Cc2ccc(Cl)cc2)c2cnccc2c1=O</smiles>

Figure 7. Pyridopyridazine derivatives as antihistaminic agents. 


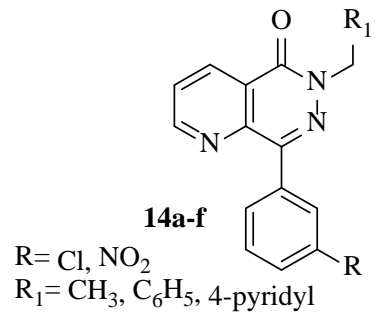<smiles>CCn1nc(-c2ccccc2)c2c(c1=O)N(C)CC(C#N)=C2C</smiles>

Figure 8. Pyridopyridazine derivatives as antiasthmatic agents.<smiles>[R]Cn1nc(CC(=O)O)c2ncccc2c1=O</smiles>

$\mathbf{1 6} \mathbf{a}=$ 5-F-2-benzothiazolyl

$\mathbf{1 6 b}=5$-CF3-2-benzothiazolyl

$\mathbf{1 6}=$ 5,7-F2-2-benzothiazolyl<smiles>[R]Cn1nc(CC(=O)O)c2cccnc2c1=O</smiles>

$17 \mathbf{a}=4-$ Br-2-F-phenyl

$\mathbf{1 7 b}=$ 5-CF3-2-benzothiazolyl

Figure 9. Pyridopyridazine derivatives as antidiabetic agents.

\subsection{Antituberculosis}

Tuberculosis (TB) is a potentially serious infectious disease that mainly affects lungs. In 1967, Kakimoto found that some derivatives of pyrido[2,3-d]pyridazine have potent anti-tuberculousis. Compounds $\mathbf{1 8}$ showed the best activity against tuberclebacilli than other aza phthlazine derivatives [25].

In 2005, J. Stanasiuk, developed another set of pyrido[3,4-d]pyridazine derivatives which have antimycobacterial activity. Compound 19 showed the strongest activity [13] (Figure 10).

\subsection{Anticancer Activity}

Cancer consists in an uncontrolled proliferation of abnormal cells. These mutated cells invade surrounding tissues and sometimes migrate through the blood or lymph spreading to other body organs causing metastases, which are the major cause of death from cancer. Although a significant proportion of cancers can be cured by surgery combined with radiotherapy or chemotherapy, especially if they are detected early, this disease is currently a leading cause of death in developed countries [26].

In 2009, J. Kaizerman et al. synthesized a new Pyrido pyridazine derivatives which showed anticancer activity. Those pyridopyridazine derivatives inhibit cascade of signals which regulate proliferation. Inhibition of proliferation could be achieved by inhibition of cyclin-dependent kinases. A survey of the literature reveals that the vast majority of kinase inhibitor scaffolds consist of planar heterocycles that present both key hydrogen bond donating and hydrogen bond accepting. Compounds 20a-d showed strong anticancer activity [10].

Recently, 2014, P. Selvakumar et al. constructed a series of pyridopyridazin-3(2H)-one derivatives. Compounds 21a-c showed potent anticancer activity against MCF-7 breast cancer cell line relative to Doxorubicin as the standard drug. The antitumor potency is belonged to the electron withdrawing substituents in the aromatic ring besides the hydrazine incorporated in those derivatives [27]. This will open new avenue to elaborate potential anticancer agents against breast cancer (Figure 11).

\subsection{Antimicrobial Activities}

Infectious diseases caused by microorganisms, bacteria, fungi and viruses have registered significant growth in recent years. The objective of microorganisms is to survive and many of them have determinants of resistance which can be expressed phenotypically as needed [28].

Elassar et al. studied various anti-microbial biological effects of some newly synthesized fused pyridine derivatives. Among that, Compound 22 showed potential antimicrobial activity [14] (Figure 12). 
<smiles>O=C1NNCc2cnccc21</smiles>

18<smiles>Cc1cc2c(=O)n(C)[nH]c(=O)c2c(=O)n1C</smiles>

19

Figure 10. Pyridopyridazine derivatives as antituberculosis agents.
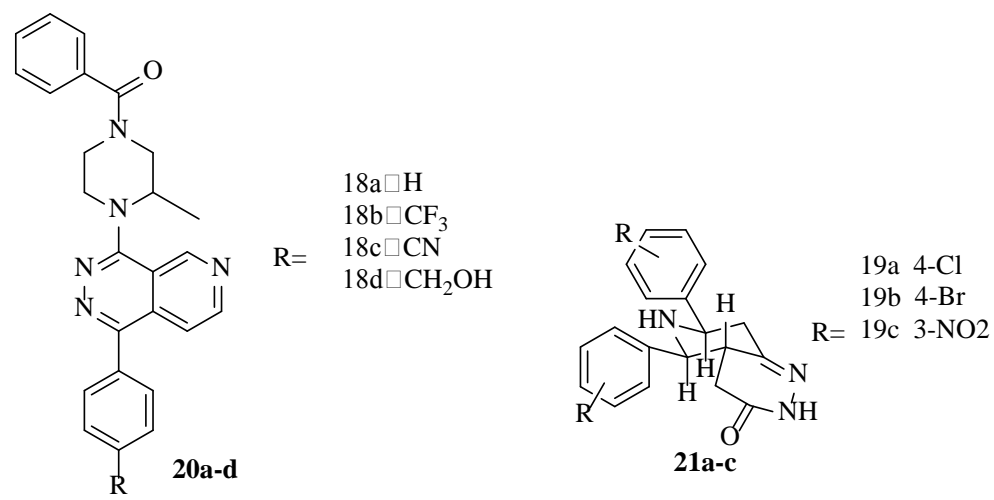

Figure 11. Pyridopyridazine derivatives as anticancer agents.<smiles></smiles>

Figure 12. Pyridopyridazine as antimicrobial agent.

\section{Conclusion}

Several biological activities of pyridopyridazines derivatives have been discussed. We can conclude that pyridopyridazine is one of the important biological active pharmacophores in medicinal chemistry. The study of this moiety may help in exploring new pathways for the researchers to discover new drugs of potential therapeutic value.

\section{References}

[1] Sainsbury, M. (2002) Heterocyclic Chemistry, Basic Concepts in Chemistry. Wiley Interscience and Royal Society of Chemistry, Bristol.

[2] Brown, D.J. (2005) 10. Halogenophthalazines (H 178; E 514). Cinnolines and Phthalazines: Supplement II, Volume 64, The Chemistry of Heterocyclic Compounds Series, John Wiley \& Sons, Inc., Hoboken, NJ, 203. http://dx.doi.org/10.1002/0471744123.ch10

[3] Hoffmann, J., Thien, T. and van'Laar, A. (1983) Effects of Intravenous Endralazine in Essential Hypertension. British Journal of Clinical Pharmacology, 16, 39-44. http://dx.doi.org/10.1111/j.1365-2125.1983.tb02141.X

[4] Meredith, P.A., Elliott, H., McSHARRY, D.R., Kelman, A.W. and Reid, J.L. (1983) The Pharmacokinetics of Endralazine in Essential Hypertensives and in Normotensive Subjects. British Journal of Clinical Pharmacology, 16, 27-32. http://dx.doi.org/10.1111/j.1365-2125.1983.tb02139.x

[5] Carling, W.R., Castro, P.J.L., Mitchinson, A. and Street, L.J. (2001) Pyrido-Pyridazine Derivatives as Ligands for Gaba Receptors. Pyrido-Pyridazine Derivatives as Ligands for Gaba Receptors. Google Patents.

[6] Gore, P.M., Looker, B.E., Procopiou, P.A. and Vile, S. (2008) Phthalazine and Pyrido[3, 4-D]pyridazine Compounds as H1 Receptor Antagonists. Google Patents.

[7] Pettus, L.H., Tasker, A. and Wu, B. (2013) Pyrido[3,2-d]pyridazine-2(1H)-one Compounds as p38 Modulators and 
Methods of Use Thereof. Google Patents.

[8] Tynebor, R.M., Chen, M-H., Natarajan, S.R., O’Neill, E.A., Thompson, J.E., Fitzgerald, C.E., et al. (2011) Synthesis and Biological Activity of Pyridopyridazin-6-one p38 MAP Kinase Inhibitors. Part 1. Bioorganic \& Medicinal Chemistry Letters, 21, 411-416.

[9] Pakulska, W., Malinowski, Z., Szczesniak, A.K., Czarnecka, E. and Epsztajn, J. (2009) Synthesis and Pharmacological Evaluation of N-(Dimethylamino)ethyl Derivatives of Benzo- and Pyridopyridazinones. Archiv der Pharmazie, 342, 41-47. http://dx.doi.org/10.1002/ardp.200800016

[10] Kaizerman. J., Lucas, B., Mcminn, D.L. and Zamboni, R. (2010) Annelated Pyridazines for the Treatment of Tumors Driven by Inappropriate Hedgehog Signalling. Google Patents.

[11] Whilhelm. R., Loe, B., Alvarez, R., Devens, B. and Fong, A. (1995) Pyrido-[2,3-d]pyridazinones as Potent and Selective type IV Phosphodiesterase Inhibitors. 8th RSC-SCI Medicinal Chemistry Symposium, Cambridge, UK, P-32.

[12] Mylari, B.L., Zembrowski, W.J., Beyer, T.A., Aldinger, C.E. and Siegel, T.W. (1992) Orally Active Aldose Reductase Inhibitors: Indazoleacetic, Oxopyridazineacetic, and Oxopyridopyridazineacetic Acid Derivatives. Journal of Medicinal Chemistry, 35, 2155-2162. http://dx.doi.org/10.1021/jm00090a002

[13] Stanasiuk, J. (2005) Investigation on the Synthesis and Properties of 2-(Alkyl, Aryl)-1,4,5-Trioxo-1,2,3,4,5,6-Hexahydropyrido[3,4-d]Pyridazine, Derivatives with Potential Biological Activity. Acta Poloniae Pharmaceutica, 63, 420421.

[14] Elassar, A.-Z.A. (2004) Synthesis and Antimicrobial Activity of New Polyfunctionally Substituted Pyridines and Their Fused Derivatives. Indian Journal of Chemistry, 43, 1314-1319.

[15] Tynebor, R.M., Chen, M.-H., Natarajan, S.R., O’Neill, E.A., Thompson, J.E., Fitzgerald, C.E., et al. (2012) Synthesis and Biological Activity of Pyridopyridazin-6-One p38 $\alpha$ MAP Kinase Inhibitors. Part 2. Bioorganic \& Medicinal Chemistry Letters, 22, 5979-5983. http://dx.doi.org/10.1016/j.bmcl.2012.07.035

[16] Bishnoi, M. and Premkumar, L.S. (2013) Changes in TRP Channels Expression in Painful Conditions. The Open Pain Journal, 6, 10-22. http://dx.doi.org/10.2174/1876386301306010010

[17] Śladowska, H., Stanasiuk, J., Sieklucka-Dziuba, M., Saran, T. and Kleinrok, Z. (1998) Investigations on the Synthesis and Properties of 4-Aminosubstituted 2,6,7-Trimethyl-1,5-Dioxo-1,2,5,6-Tetrahydropyrido[3,4-d]Pyridazines. Il Farmaco, 53, 475-479. http://dx.doi.org/10.1016/S0014-827X(98)00051-2

[18] Epsztajn, J., Czarnecka, E., Szczesniak, A., Pakulska, W. and Malinowski, Z. (2009) Benzo- and Pyrido-Pyridazinones with Analgesic and Antiinflammatory Activity. Google Patents.

[19] Nishikawa, K., Shimkawa, H., Inada, Y., Shibouta, Y., Kikuchi, S., Yurugi, S. and Oka, Y. (1976) Structure-Activity Relationships of the Diuretic Activity of Triaza- and Tetraaza-Naphthalene Compounds. Chemical \& Pharmaceutical Bulletin, 24, 2057-2077. http://dx.doi.org/10.1248/cpb.24.2057

[20] Goodacre, S.C. and Hallett, D.J. (2006) Substituted Pyrido-Pyridazine Derivatives Which Enhance Cognition via the GABA-A Receptors. Google Patents.

[21] Mitchinson, A., Blackaby, W.P., Bourrain, S., Carling, R.W. and Lewis, R.T. (2006) Synthesis of Pyrido [2,3-d]Pyridazines and Pyrazino[2,3-d]-Pyridazines-Novel Classes of GABA Receptor Benzodiazepine Binding Site Ligands. Tetrahedron Letters, 47, 2257-2260. http://dx.doi.org/10.1016/j.tetlet.2006.01.084

[22] Kurosawa, M. (1995) Role of Thromboxane $A_{2}$ Synthase Inhibitors in the Treatment of Patients with Bronchial Asthma. Clinical Therapeutics, 17, 2-10. http://dx.doi.org/10.1016/0149-2918(95)80002-6

[23] Dal, P.V., Giovannoni, M.P., Castellana, C., Palacios, J.M., Beleta, J., Doménech, T., et al. (1997) Novel HeterocyclicFused Pyridazinones as Potent and Selective Phosphodiesterase IV Inhibitors. Journal of Medicinal Chemistry, 40, 1417-1421. http://dx.doi.org/10.1021/jm970105l

[24] Zimmet, P., Alberti, K. and Shaw, J. (2001) Global and Societal Implications of the Diabetes Epidemic. Nature, 13, 782-787. http://dx.doi.org/10.1038/414782a

[25] Kakimoto, S. and Tonooka, S. (1967) Antituberculous Compounds. XXV. Some Derivatives of Pyrido [2,3- $d$ ] Pyridazine. Bulletin of the Chemical Society of Japan, 40, 153-159. http://dx.doi.org/10.1246/bcsj.40.153

[26] Cancer. 18 November 2014. http://www.who.int/cancer/en/

[27] Selvakumar, P., Thennarasu, S. and Mandal, A.B. (2014) Synthesis of Novel Pyridopyridazin-3(2H)-One Derivatives and Evaluation of Their Cytotoxic Activity against MCF-7 Cells. International Scholarly Research Notices, 2014, Article ID: 410716. http://dx.doi.org/10.1155/2014/410716

[28] Rennie, R.P. (2012) Current and Future Challenges in the Development of Antimicrobial Agents. In: Coates, A.R.M., Ed., Antibiotics Resistance, Handbook of Experimental Pharmacology, Vol. 211, Springer-Verlag, Berlin, 45-65. http://dx.doi.org/10.1007/978-3-642-28951-4_4 